\title{
Lattice Deformation and Curvature in Stalactitic Carbonate
}

\author{
Paul L. Broughton*
}

SUMMARY

The cause of lattice curvature is related to the nature of growth on a curved surface, peculiar to stalactites and stalagmites. Lattice curvature in stalactic carbonate results from the coalescence of sub-parallel to divergent syntaxial overgrowth crystallites on the growing surface of stalactites and stalagmites. Moderate lattice mismatch results in an undulose extinction, or subcrystal domains, whereas more divergent growth favours marked lattice curvature recognized by its optical brush-extinction. Extreme lattice mismatch between the precursor crystallites results a columnar crystal boundary instead of lattice curvature.

\section{INTRODUCTION}

Most stalactitic carbonate is in a radial fabric. Recent investigations on the growth by Kendall and Broughton (1977, 1978) and Broughton (1983) have interpreted this fabric to be a secondary mosaic arising from the coalescence of precursor syntaxial overgrowths. This fabric of length-fast calcite crystals is typical of stalactites, but many other types of carbonate mosaic (some aragonitic) are present. This paper investigates an important variation of normal radial fabric growth. Although relatively rare, stalactitic growth characterized by apparent lattice deformation or curvature is a predictable consequence of the Kendall and Broughton theory cn the origin and growth of stalactites by coalescing syntaxial crystallite overgrowths. The objective of this paper is to provide petrographic and pe-

*Present Address: Home Oil Company, 1700 Home Oil Tower, 324 - 8 Avenue, S.W., Calgary, Alberta, Canada 
trologic information on lattice deformation in speleothem crystals.

Fabrics related to lattice curvature or deformation are relatively rare, and have been observed as portions of less than 5 per cent of the specimens. Nevertheless, they are sufficiently widespread to be considered an important mechanism for elucidating the growth of stalactitic carbonate.

\section{MATERIALS}

This study is based on a couple of hundred petrographic sections cut from almost an equivalent number of stalactites and stalagmites. Many of these samples lack locations or are poorly located, and much of this material has been secured from existing museum collections, individual contributions, and removed from caves ahead of quarrying cperations. This research is suggested to be independent of locality data, and for this reason, it has not been given in the figure descriptions.

\section{NOMENCLATURE}

Some ambiguity persists regarding the terms used to describe crystal forms. Acicular is used in this paper to describe materials composed of needle-like, markedly elongate and pointed crystals less than 5 microns wide, regardless of mode of packing, and includes fabrics often referred to as fibrous (closely packed acicular).

Columnar is used to describe crystals that are elongate and wider than 10 microns. Subcrystal is ambiguous, but is used as partially synonymous with domain, and usually recognized by optically uniform extinction. Material deposited on a portion of the crystal's growth surface that is separated from other parts by having discrete crystallite faces is a second type of subcrystal growth referred to in this paper as a syntaxial overgrowth crystallite. This terminology is adopted from earlier studies on speleothem carbonates by Kendall and Broughton (1978) and Broughton (1983).

\section{THE LATTICE DEFORMATION FABRIC}

Deformation (malformation) of the calcite (and aragonite) crystals is characterized by curved or divergent crystallogra- 
phic axes. This is commonly the c-axis in a length-fast columnar calcite crystal, but may be the a-axis in the rarely observed length-slow fabric. There are a number of fabric types recognized as having optical characteristics of lattice curvature or deformation. The following types are usually restricted to a portion of a stalactite:

Type 1. Fabrics observed in selected stalactite and stalagmite specimens have extensively subdivided elongate subcrystals which differ in crystallographic orientation. It is difficult in some specimens to distinguish separate crystals because of this subdivision and what may be considered to be separate crystals in one area of a stalactite must be considered sub-crystals in another (Fig. 1).

Type 2. Systematic and uniform change in extinction position in sections cut normal to the long axis of these stalactites indicates that the fast-vibration directions in each crystal diverge away from the stalactite centre (Fig. 2). This is a common variant of lattice deformation, and is observed more or less in most stalactites and stalagmites. An undulose extinction is characteristic and results from a gradual change of crystallographic orientation across a population of domains, each slightly disoriented with regard to its neighbours.

Type 3. Brush extinction in sections cut normal to the axis of the stalactite caused by curved domains (Fig. 3). The c-axes of domains are curved, divergent from the axis of the stalactite. The crystals are length-fast.

Type 4. Brush extinction in sections cut normal to the axis of the stalactite caused by length-slow domains (Fig. 4). The a-axes are convergent.

These lattice distortions in stalactitic carbonate could not have arisen by the application of external stress, and suggest a relationship to the original growth mechanism. To investigate the origin of such lattice curvature, it is first necessary to elucidate the normal growth mechanism commonly observed in most portions of stalactites and stalagmites.

\section{NATURE OF NORMAL RADIAL COLUMNAR CRYSTAL GROWTH}

Most stalactitic carbonate growth is not by competitive crystal growth as suggested by Prinz (1906) and reiterated by Moore (1962), nor is it a neomorphic replacement texture as proposed by Thrailkill (1976). The arguments precluding these alternative theories are documented in Kendall and Broughton (1978) and Broughton (1979). They are summarized as follows. 
Inclusions and the patterns that they make are the most important evidence for interpretating the origin and growth of stalactitic carbonates. Inclusions are trapped by the advancing growth surface and variations in either the supply or the rate of impurity absorption give rise to variations in inclusions concentration, which define the growth layering. Most inclusions are fluid, and are portions of the water film trapped by the carbonate precipitation on the growth surface. The orientation of the elongate inclusions between former faces must be kept in mind when viewing crystals with undulose extinction to distinguish those caused by heterogeneous chemical composition of a single crystal or by impurities causing development of screw dislocations. These also may result in malformed crystal lattices, but have not been demonstrated to exist in cave calcites.

There are several types of growth layers recognized in normal radial columnar crystal growth. One of the most common is a growth layer defined by parallel to sub-parallel linear inclusions. Each lineation parallels the optic axis orientation of the host crystal when this is oblique to the growth surface. The layers of these inclusions are more often than not smooth curves, but may also define former positions of rhombohedral crystal faces and terminations. Such crystal terminations may also be defined by extremely fine, non-linear inclusions that impart a pseudo-pleochoric brown band colouration. The most common layers are essentially inclusion-free, i.e. clear calcite, and occur between the above types. Layers that are distinguished by occurrence of large quantities of opaque impurities, that the crystal fabrics are partially to completely obscured, are relatively rare. It is a popular misconception as to the dominance of this latter growth type.

Fig. 1 - Domains in columnar crystals.

The c-axes grew approximately normal to the plane of the section, but their slight divergence had sufficient lattice mismatch to impart a lattice deformation and irregular extinction without formation of a grain boundary. Cross-polarized light. Bar scales are 0.3 $\mathrm{mm}$ in cross-polarized light.

A:Cross-section of a mosaic of irregular blocky crystals formed by the Coalescence of acicular crystals with moderate lattice mismatch This resulted in squat columnar crystals with patchy optical extinction indicative of subcrysttl domains with poorly defined boundaries. Note preservation of the precursor acicular crystal terminations on a growth surface (arrows).

B: A monocrystalline central canal resulting from coalesced trigonal crysials whose c- and a-axes are more or less regulary aligned. The moderate divergence infilling a circular section induced a radially-oriented lattice distortion. 

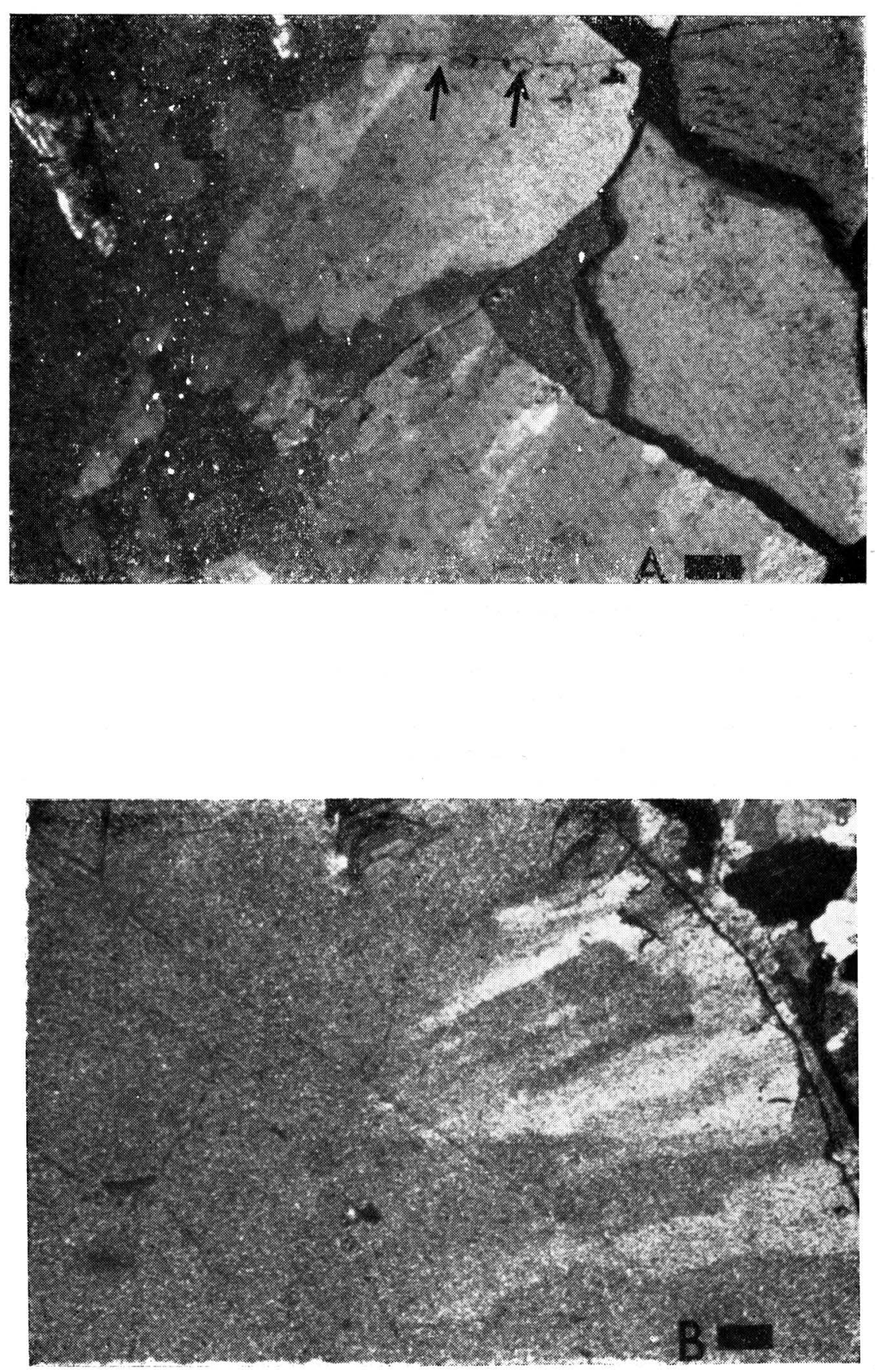
Most of the inclusions are fluid-filled cavities, and growth layers defined by parallel, linear inclusions are interpreted to represent remnants of former inter-crystallite spaces formed during incomplete lateral coalescence of numerous syntaxial overgrowth crystallites which grow on the speleothem surface. Complete crystallite coalescence generates the inclusion-frec calcite, whereas inhibition of the lateral coalescence of the overgrowth crystallites generates layers of acicular calcite. Thus formed acicular calcite may later merge as clear calcite with linear inclusions (in which case the inclusions are remnants of former inter-acicular boundaries).

Stalactite growth is interpreted as innumerable crystallites which coalesce immediately behind the growing surface to generate columnar crystals. Thin coalescence is possible because each crystallite is a syntaxial overgrowth of the same crystal as its neighbors. Thus, adjacent crystallites possess near-identical lattice orientations and can coalescence or combine into a single crystal.

The gradual passage that often occurs between layers of acicular and layers of columnar calcite would, at first sight, suggest a replacement of an acicular precursor. However, the derivation of most inclusion-bearing columnar crystals from an acicular precursor is unlikely because in actively-growing stalactites the columnar crystals commonly extend all the way to the growing surface. There is no room for any acicular precusor. The change from acicular to columnar crystal growth layers, which suggested an acicular precursor, is concluded to be a variation in the degree of overgrowth coalescence with time.

\section{Origin of Crystal Boundaries and Subcrystals}

Crystal boundaries in stalactitic carbonate are interpreted not as the consequence of the larger columnar crvstals interacting, but related to the precursor syntaxial crystallite overgrowths on the columnar crystals. Each columnar crystal has numerous terminations along the growing surface and when such crystals grow towards each other the compromise boundary between them must of necessity be jagged or serrated.

The perfection of any crystal will depend upon the manner by which the variouis centres of growth come together. Crystals that originate from growth on large planar crystal faces exhibit greater perfection than those which are generated by the 
amalgamation of numerous crystallites on a curved or irregular growth surface.

\section{LATTICE DEFORMATION IN CRYSTALS}

\section{Origin of Crystal Fabrics.}

The presence of lattice deformation in crystals implies that crystallites with slightly divergent crystallographic orientations can, and do, combine during their lateral growth into single crystal units. Such coalescence is clearly only possible when adjacent crystallites possess nearly-identical lattice orientations such that the lattice mismatch between them can be accomodated within planes of dislocation. The origin of this sub-parallel to moderately divergent growth of neighbouring crystallites is because of the curved growth surface peculiar to stal-

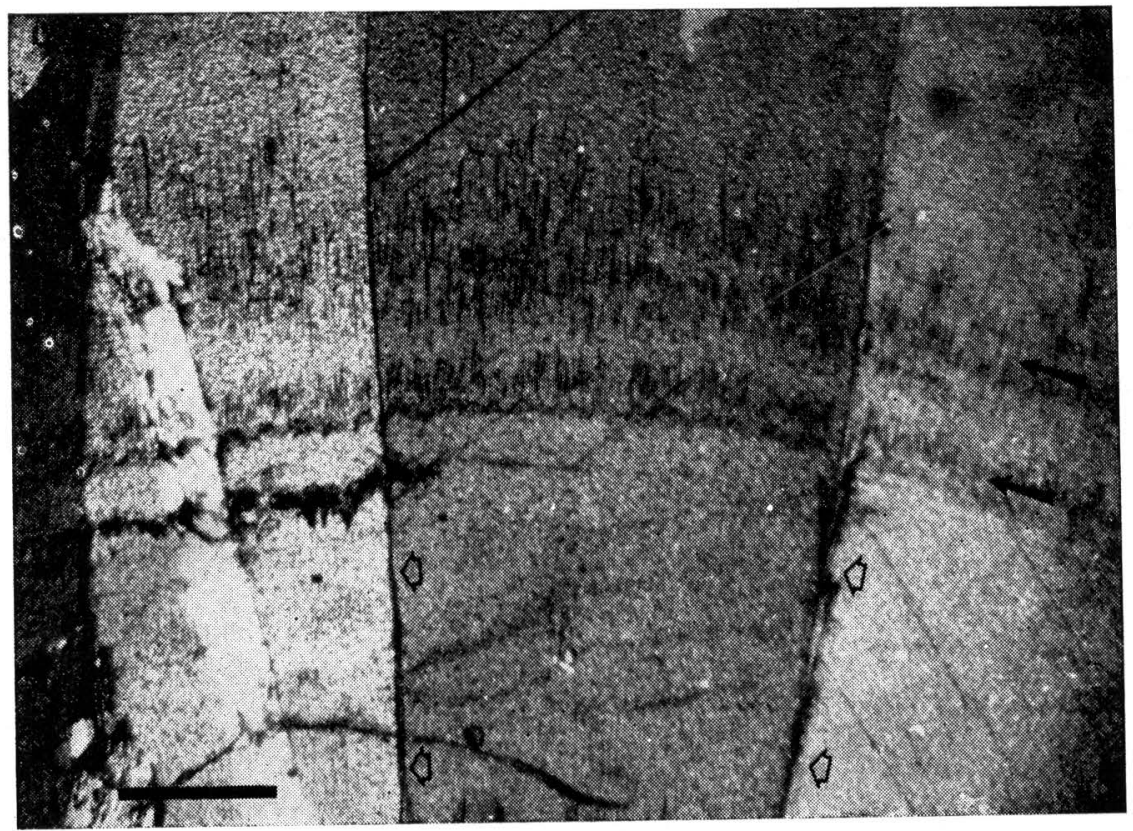

Fig. 2 - Growth layers (closed arrows) defined by linear inclusions which exhibit a slight but gradual change in orientation across the crystals. These paralleled a similar variation in the optic axis orientation on a curved surface, and resulted in formation of grain boundaries (open arrows). Cross polarized light. Bar scale is 0.5 $\mathrm{mm}$. 
actitic carbonate, hence a certain degree of lattice mismatch in the direction of growth is normal. This may result in an undulose ex"inction (type 2 ) in a columnar crystal without the formation of domains if the directions of growth (hence, the c-axes) of the crystallite overgrowths are oriented normal to a smoothly curved growth surface (Fig. 2). At some point the divergent axes are no longer able to coalesce because of sufficiently divergent lattic, mismatch. A boundary between the columnar crystals results.

When the crystallographic orientations and growth directions are sub-parallel, then the coalescence between crystallites during lateral growth can be moderately accomodated within planes of dislocation. This results in poorly defined domains with indistinct boundaries caused by changes in the allegiance during lateral coalescence. This is relatively common in monocrystalline stalactites and soda-straw fill (Fig. 1, B). While similar, parallel to sub-parallel orientation of the c-axes of neighbouring crystallites favours formation of a single crystal, the slight lattice mismatch of the a-axes also results in domains with irregular, more or less well-defined, boundaries. Since crystallites on the growth surface adopt the crystallographic orientation of the columnar crystal substrate, their c-axes as well as a-axes (and b-axes in aragonite) are similarly oriented. The optical continuity suggesting lattice continuity confirms this. If there were random orientation, then crystal coalescence could be achieved only by a rotation of some acicular or crystallite lattices relative to each other. No mechanism is known that could cause such a rotation.

The most pronounced lattice curvature results in a brush extinction with clearly defined curved domains (Types 3 and 4). The c-axes are divergent away from a common origin when length-fast (Fig. 3), or convergent when length-slow (Fig. 4). It is uncertain whether divergent crystallites on the growing surfaces should be considered as multiple terminations upon an already deformed calcite lattice, in which case the domains are analogous to overgrowths upon "strained" quartz grains (Waugh, 1970) or if precipitation upon curved growth surfaces

Fig. 3 - Extreme lattice curvature caused by divergent crystallographic axes.

A: Cross-section of stalactite with sufficiently divergent c-axes that partially coalesced crystals have curved former faces. Plane polarized light.

B: The lattice curvature of fig. A, when viewed under cross-polarized light, exhibits a brush-extinction.

Scanning electron micrograph of lattice curvature. Note the lattice deformation induced by realignment of c-caves along a curved growth path. Bar scales in A and B are $0.3 \mathrm{~mm}$ and 50 microns in C. 

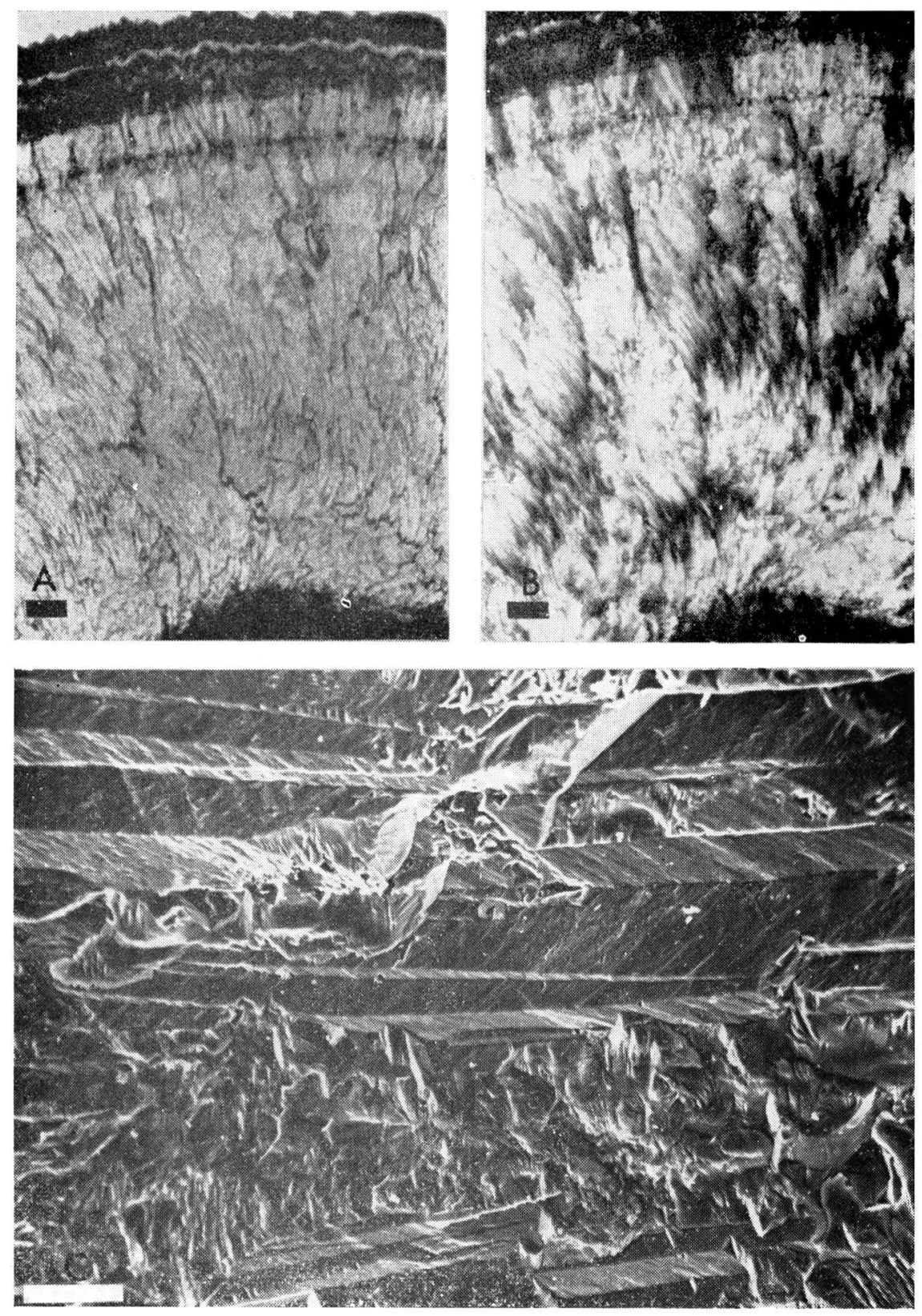
in some manner promotes the formation of radially (and therefore divergently) oriented crystallites and the deformed crystals are a product of their coalescence. It is probable that both variations are possible with different episodes of stalactitic growth.

\section{DISCUSSION}

\section{Acicular Crystal Replacement and Lattice Curvature}

The elongate inclusions in columnar crystals arising from coalesced syntaxial overgrowths on a curved growth surface are linearly arranged within each crystal and diverge from a common origin at or below the substrate boundary. This pattern is similar to the fascicular-optic calcite mosaic described by Kendall (1977) as a replacement after bundled acicular crystals. Only the isopachous distribution of the fascicular-optic calcite in cavities of deep-water (marine) limestones serves to distinguish the fabric. It is difficult to distinguish replacements of acicular cements, in which case the inclusions are remnants of former acicular boundaries, in which crystal "coalescence" occurred at a much later date. The distinction on fabric evidence alone may not be possible between replacement after crystal growth from an acicular cement versus coalescence during crystal growth from syntaxial overgrowths. Either mechanism results in radially diverging optic axes that exhibit an undulose extinction.

\section{CONCLUSIONS}

The columnar crystals that characterize the fabric of most stalactitic carbonate form by a process of syntaxial crystallite coalescence, immediately behind the growth surface. Incomplete lateral coalescence of crystallites leaves remnants of the former inter-crystallite spaces as fluid-filled, linear cavities within the columnar crystals. Acicular calcite forms from the overgrowth crystallites in the absence of this lateral coalescence. Failure to coalesce may be the consequence of ion absorption. The crystallites adopt the crystallographic orientation of the columnar crystal substrate and as such the syntaxial overgrowths are normally aligned parallel. However, continued 
growth on the curved surface of a stalactite results in sufficient crystallographic divergence that either the columnar crystal forms a boundary or coalescence is possible with lattice deformation characteristics. Coalescence of moderately divergent crystallites results in a columnar crystal with an undulose extinction, but greater divergence (or the rare convergonce of a-axes in length-slow calcite) results in domains (subcrystals). Depending upon orientation between adjacent crystallites, extreme lattice curvature with divergent optic and crystallographic axes may result in brush-extinction characteristics.

Any subsequent replacement of acicular calcite or aragonite by a columnar crystal will assume the crystallographic orientation of the divergent optic axes. Such a fabric will display a strained lattice with an undulose extinction. It is difficult to demonstrate that such a crystal " coalescence " has occurred at a much later date. The distinction between the two mosaics (coalesced syntaxial overgrowths and replaced acicular crystals with coalescence after crystals growth) may not be possible on fabric evidence alone.



Fig. 4 - A rare variety of lattice curvature along the a-axes (length-slow) resulting in a mosaic of convergent, cusp-like crystals. These crystals grew within a layer of iron oxide detritus. Fig. A is crosspolarized light, and $\mathrm{B}$ is plane-polarized light. Bar scaies are 0.3 $\mathrm{mm}$. 


\section{ACKNOWLEDGMENTS}

This paper is a further specialized study based on an inquiry into the general origin and growth of stalactitic carbonate in collaboration with A.C. Kendall (Amoco Canada Petroleum Company, Alberta). Research facilities were provided by the Department of Mineral Resources (Regina, Saskatchewan) and the Department of Geology, University of Cambridge. Appreciation is expressed to many members of the National Speleological Society (Huntsville, Alabama), many of whom wish to remain ananymous, for providing the many specimens upon which this study was based.

\section{REFERENCES}

BROUGHTON, P.L., 1983. Secondary origin of the radial fabric in stalactitic carbonate. Int. J. Speleo., (this volume).

KENDALL, A.C., 1977. Fascicular-optic calcite: a replacement after bundled acicular carbonate cement. J. Sed. Petrology, 45: 1056-1062.

KENDALL, A.C. and BROUGHTON, P.L., 1977. Discussion: calcite and aragonite fabrics Carlsbad Caverns, by R.L. Folk and R. Assereto (J. Sed. Petrology, v. 46, p. 486-496): J. Sed. Petrology, 47: 1397--1400.

KENDALL, A.C. and BROUGHTON, P.L., 1978. Origin of fabrics in speleothems composed of columnar calcite crystals. J. Sed. Petrology, 48: 519-538.

MOORE, G.W., 1962. The growth of stalactites. Buil. Natl. Speleo. Soc., 24: 95-106.

PRINZ, A., 1906. Les cristallisations des grottes de Belgique. Nouv. Mem. Soc. Belge. Geol., 1-90.

TRAILKILL, J., 1976. Speleothems: In Walter, M.R. (ed.), Stromatolites, Developments in Sedimentology 20, Elsevier, Amsterdam, 73-86.

WAUGH, B., 1970. Formations of quartz overgrowths in the Penrith Sandstone (Lower Permian) of northwest England as revealed by scanning electron microscopy. Sedimentology, 14: 309-320. 